\title{
Precision synthesis of reducing-end thiol-modified cellulose enabled by enzyme selection
}

\author{
Chao Zhong ${ }^{1} \cdot$ Bernd Nidetzky ${ }^{1,2}$
}

Received: 22 October 2021 / Revised: 4 November 2021 / Accepted: 5 November 2021 / Published online: 3 December 2021

(c) The Author(s) 2021. This article is published with open access

\begin{abstract}
Enzyme-catalyzed iterative $\beta$-1,4-glycosylation of $\beta$-glycosides is promising for bottom-up polymerization of reducing-endmodified cello-oligosaccharide chains. Self-assembly of the chains from solution yields crystalline nanocellulose materials with properties that are tunable by the glycoside group used. Cellulose chains with a reducing-end thiol group are of interest to install a controllable pattern of site-selective modifications into the nanocellulose material. Selection of the polymerizing enzyme (cellodextrin phosphorylase; CdP) was pursued here to enhance the synthetic precision of $\beta$-1-thio-glucose conversion to generate pure "1-thio-cellulose" ( $295 \%)$ unencumbered by plain (unlabeled) cellulose resulting from enzymatic side reactions. The CdP from Clostridium stercorarium $(C s \mathrm{CdP})$ was 21 times more active on $\beta$-1-thio-glucose $\left(0.17 \mathrm{U} / \mathrm{mg} ; 45^{\circ} \mathrm{C}\right)$ than the $\mathrm{CdP}$ from Clostridium cellulosi $(C c \mathrm{CdP})$, and it lacked hydrolase activity, which is substantial in $C c \mathrm{CdP}$, against the $\alpha$-D-glucose 1-phosphate donor substrate. The combination of these enzyme properties indicated that $C s \mathrm{CdP}$ is a practical catalyst for 1-thio-cellulose synthesis directly from $\beta$-1-thio-glucose ( $8 \mathrm{~h} ; 25 \mathrm{~mol} \%$ yield) that does not require a second enzyme (cellobiose phosphorylase), which was essential when using the less selective $C c \mathrm{CdP}$. The 1-thiocellulose chains had an average degree of polymerization of $\sim 10$ and were assembled into highly crystalline cellulose II crystallinity material.
\end{abstract}

\section{Introduction}

Cellulose is an abundant and eco-friendly natural polymer and represents an extremely versatile material. In particular, nanosized celluloses ("nanocelluloses") have attracted significant interest for material use and offer a unique combination of material properties, including high surface area, high porosity, suitable pore interconnectivity, and high mechanical flexibility [1-3]. They also show good biocompatibility in general, which makes them promising for medical engineering $[4,5]$ and tissue engineering applications $[6,7]$. Chemical

Supplementary information The online version contains supplementary material available at https://doi.org/10.1038/s41428021-00599-4.

Bernd Nidetzky

bernd.nidetzky@tugraz.at

1 Institute of Biotechnology and Biochemical Engineering, Graz University of Technology, NAWI Graz, 8010 Graz, Austria

2 Austrian Centre of Industrial Biotechnology (ACIB), 8010 Graz, Austria derivatization is frequently used to diversify the structural properties of nanocelluloses, with the aim of expanding the scope of their applications. However, sustainable production of nanocellulose from natural celluloses represents an important issue $[8,9]$. Moreover, the preparation of chemically derivatized nanocelluloses that incorporate a welldefined pattern of functional groups remains a considerable challenge for material synthesis. In addition to the poor solubility of cellulose in common solvents, chemical derivatizations usually present difficult control of selectivity (e.g., site control) $[10,11]$. Therefore, precise synthesis methods that enable the facile preparation of tailor-made nanocelluloses with tunable functional properties would be highly desirable in cellulose polymer chemistry. The classical topdown approach in two steps, namely, the release of nanocelluloses from natural cellulosic material and their subsequent chemical derivatization [12], encounters limitations, particularly in the last step, for achieving precise functionalization.

Bottom-up synthesis of derivatized cellulose chains has been explored as an alternative for overcoming these limitations to some degree. The bottom-up approach involves a reversed order of events wherein chemical functionalization 
Scheme 1 Synthesis of cellulose material from 1-thio- $\beta$-D-glucose and $\alpha$ Glc1-P through a coupled (CbP-CdP) and b single (CsCdP) enzyme reactions a)
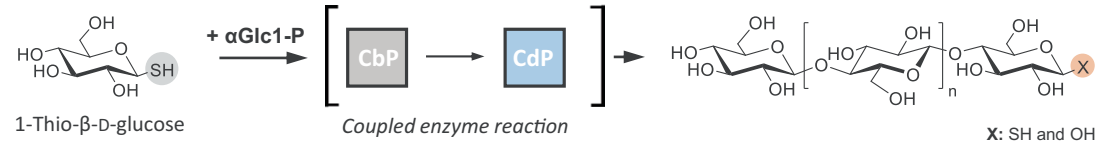

b)

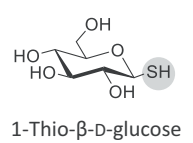

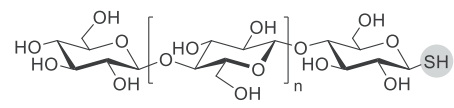

Reducing-end thiol-modified cellulose occurs before cellulose chain polymerization [13, 14]. Thus, higher synthesis precision (e.g., degree of polymerization (DP) or modification control) is offered compared with that typically achievable by top-down processing. Both chemical and enzymatic routes are known for the bottom-up synthesis of cellulose [13-16]. Despite progress in chemistry [17], a polymerization reaction that exploits the reactivity enhancement and selectivity control of an enzyme is highly desirable [13]. To date, several classes of enzymes, including cellulose synthase, cellulase, glycosynthase, and glycoside phosphorylase, have been used for the synthesis of cellulose chains $[14,18]$. A variety of cellulose materials built from $\beta$-1,4-polyglucose chains with a DP of up to 200 were produced through iterative glycosylation of cellobiose $[19,20]$, glucose [21, 22], or derivatives thereof [23-25]. The introduced chemical modifications were mostly at the "reducing end", with exceptions noted [25]. Reducing-end modifications result from glycosides being glycosylated [23-25]. These bottom-up synthetic approaches are highly flexible in general and open the door to the synthesis of tailor-made nanocelluloses, thus bringing the possibility to regulate the functionality of cellulose materials.

Thiol is a chemically reactive group that has attracted considerable attention for the functionalization of polymeric surfaces, including cellulose [26]. A family of thiol-based chemistries, such as thiol-ene [27], thiol-yne [28], thiolisocyanate [29], and thiol-halo reactions [30], are excellent synthetic tools to introduce novel functions into cellulose materials (for details, see reviews [27, 28, 31]). In addition, thiol group interactions with metals (e.g., silver and gold) are promising for nanocellulose materials. By virtue of the high surface area offered, "1-thio-cellulose" materials would be excellent candidates for templating metal nanoparticles [32, 33]. Despite the application potential, the synthesis of thiol-modified celluloses has not been well explored, particularly using enzymatic routes of preparation. In our recent study, a bottom-up synthesis of reducingend thiol-modified cellulose was shown [32]. A twophosphorylase cascade reaction was used that involved cellobiose phosphorylase (CbP, EC 2.4.1.20) and cellodextrin phosphorylase (CdP, EC 2.4.1.49). Both enzymes (CbP from Cellulomonas uda, CuCbP; $\mathrm{CdP}$ from Clostridium cellulosi, $C c \mathrm{CdP}$ ) employ $\alpha$-D-glucose 1-phosphate
( $\alpha$ Glc1-P) as the donor substrate. The overall iterative $\beta$-1,4-glycosylation starts from 1-thio- $\beta$-D-glucose as the "primer" substrate (Scheme 1a), and 1-thio-cellooligosaccharides of DP between 6 and 11 are released in the process. Self-assembly of the oligosaccharides produces a material with a nanosheet-like morphology and high cellulose II crystallinity. Nuclear magnetic resonance (NMR) data show that the synthesized 1-thio-cellulose contained $\sim 40 \%$ unlabeled material. Given the high purity of the 1 -thio- $\beta$-D-glucose precursor used, plain cellulose chains are formed as a consequence of side reactions catalyzed by the enzymes. In particular, $C c \mathrm{CdP}$ shows weak hydrolase activity on $\alpha \mathrm{Glc1}-\mathrm{P}$, and the released glucose is used to produce plain cellulose chains by $C u \mathrm{CbP}$ and $C c \mathrm{CdP}$ working in combination (Supplementary Fig. S1). The relative content of 1-thio-cellulose chains in the modified cellulose may be difficult to control, especially under conditions when the activities of $C u \mathrm{CbP}$ and $C c \mathrm{CdP}$ are varied for optimization of the synthesis. Considering restrictions on the applicability of 1-thio-cellulose arising from contamination with unlabeled material, we explored enzyme selection to enhance the synthetic precision. The CdP from C. stercorarium $(C s \mathrm{CdP})$ was identified to have superior kinetic properties to $C c \mathrm{CdP}$. We showed that $C s \mathrm{CdP}$ can be used for the synthesis of pure 1-thio-cellulose $(\geq 95 \%)$ directly from 1-thio- $\beta$-D-glucose in a single-enzyme reaction without the requirement of additional $C u \mathrm{CbP}$. The resulting 1-thio-cellulose was characterized chemically (NMR and matrix-assisted laser desorption ionization time-of-flight mass spectrometry (MALDI-TOF MS)) and as a solid material (X-ray diffraction (XRD) and infrared spectroscopy). The bottom-up synthesized, pure 1-thio-cellulose can facilitate further functional diversification of nanocellulose materials.

\section{Experimental procedures}

\section{Materials}

The materials used were of reagent grade and obtained from Sigma-Aldrich (Vienna, Austria) or Carl Roth (Karlsruhe, Germany). 


\section{Enzymes}

$\mathrm{Cu}$ CbP (GenBank ID, AAQ20920.1) and $C c \mathrm{CdP}$ (GenBank ID, CDZ24361.1) were obtained by previously reported methods [19]. CsCdP (GenBank ID, U60580.1) was expressed in Escherichia coli BL21(DE3) using a plasmid vector $(\mathrm{pET}-21 \mathrm{~b}(+))$ harboring the codon-optimized gene (GenScript Biotech Corp., N.J., U.S.) under the control of a T7 promoter (Supplementary Fig. S2). Enzyme expression in $E$. coli strains was induced by isopropyl $\beta$-D-1-thiogalactopyranoside $(C u \mathrm{CbP}: \quad 0.1 \mathrm{mM} ; \quad C s \mathrm{CdP}: \quad 0.05 \mathrm{mM}$; Cc CdP: $0.25 \mathrm{mM}$ ) at $18^{\circ} \mathrm{C}$ overnight. Afterward, enzymes were purified using a prepacked $(1.6 \mathrm{~cm} \times 2.5 \mathrm{~cm} ; 5 \mathrm{~mL})$ HisTrap FF crude column (GE Healthcare Europe, Vienna, Austria) on an ÄKTA prime plus system (GE Healthcare Europe). The His-tagged proteins were eluted with imidazole $(0.01-0.30 \mathrm{M})$. The purified proteins were desalted using MES buffer $(50 \mathrm{mM}$, pH 7.0) with Vivaspin Turbo $50 \mathrm{kDa}$ cutoff tubes (Sartorius Stedim, Vienna, Austria). Note that additional heat treatment at $65-70{ }^{\circ} \mathrm{C}$ for 15-30 min was necessary to obtain highly purified $C s \mathrm{CdP}$. The protein concentration was measured using a ROTI Quant assay (Carl Roth, Karlsruhe, Germany) referenced against bovine serum albumin.

\section{Enzyme activity assay}

Enzyme activities were determined by previously reported methods [19]. Briefly, the activities of phosphorylase were determined at $45{ }^{\circ} \mathrm{C}$ in the direction of synthesis. A $50 \mathrm{mM}$ MES buffer (pH 7.0) that contained the substrates $50 \mathrm{mM}$ glucose $(\mathrm{CuCbP})$ or $50 \mathrm{mM}$ cellobiose $(C c \mathrm{CdP}$ and $C s \mathrm{CdP}$ ) and $50 \mathrm{mM} \alpha \mathrm{Glc} 1-\mathrm{P}$ was used. The released phosphate was measured by colorimetric detection [34]. In addition, the activity with the acceptor 1 -thio- $\beta$-D-glucose $(50 \mathrm{mM})$ was determined for each enzyme. One unit (U) of activity is equivalent to the enzyme amount that produces $1 \mu \mathrm{mol}$ phosphate/min under the conditions employed.

\section{Bottom-up synthesis of 1-thio-cellulose}

Synthesis reactions were carried out at $45^{\circ} \mathrm{C}$ and $300 \mathrm{rpm}$ agitation through incubation in plastic tubes $(0.5 \mathrm{~mL}$ volume) on a ThermoMixer C (Eppendorf, Vienna, Austria). Reaction solutions were produced in MES buffer (50 mM, pH 7.0) containing donor $\alpha \mathrm{Glc} 1-\mathrm{P}(100 \mathrm{mM})$ and acceptor 1 -thio- $\beta$-D-glucose $(10 \mathrm{mM})$. The enzymes used were $C s C d P(0.1 \mathrm{mg} / \mathrm{mL}), C s C d P(0.08 \mathrm{mg} / \mathrm{mL})$ and $C u \mathrm{CbP}(0.06 \mathrm{mg} / \mathrm{mL})$, or $C c \mathrm{CdP}(0.08 \mathrm{mg} / \mathrm{mL})$ and $C u \mathrm{CbP}(0.06 \mathrm{mg} / \mathrm{mL})$. The enzymes were used to give reasonably similar volumetric activities for reaction with 1-thio- $\beta$-D-glucose: $C s \mathrm{CdP}, \sim 0.02 \mathrm{U} / \mathrm{mL} ; C u \mathrm{CbP}, \sim 0.04$
$\mathrm{U} / \mathrm{mL}$. The reaction time varied between 8 and $12 \mathrm{~h}$ depending on the conditions used. The blank of each reaction used identical conditions but lacked the substrate 1 -thio- $\beta$-D-glucose.

All synthesis reactions yielded insoluble material as a white precipitate. The insoluble material was centrifuged off $(15,000 \mathrm{rpm}, 5 \mathrm{~min})$ and washed three times with distilled water. Approximately $0.5 \mathrm{~g}$ wet material was lyophilized for further analysis.

\section{Cellulose material characterization}

X-ray diffraction (XRD) was performed for the lyophilized cellulose using a D8 Advance powder diffractometer (Bruker AXS, Karlsruhe, Germany). The instrument with Bragg-Brentano geometry was run using a Bruker LYNXEYE SuperSpeed Detector at room temperature. The instrument was operated at $40 \mathrm{kV}$ and $40 \mathrm{~mA}$ using $\mathrm{Cu}-\mathrm{K} \alpha$ radiation $(\lambda=0.15418 \mathrm{~nm})$. Diffraction angles were measured from $5^{\circ}$ to $60^{\circ} 2 \theta$, with a step size of $0.02^{\circ} 2 \theta$ and $5 \mathrm{~s}$ per step.

Attenuated total reflection-Fourier transform infrared (ATR-FTIR) spectrometry was performed to determine the absorption spectra of cellulose materials using a Bruker ALPHA FTIR spectrometer (Bruker Optik, Ettlingen, Germany) and an ATR accessory with a diamond window. The cellulose suspension $(\sim 2 \mathrm{mg} / \mathrm{mL}$, in water) was air dried on the sample holder before measurement. The spectra were recorded at room temperature in a range of $4125-375 \mathrm{~cm}^{-1}$ at a spectral resolution of $2 \mathrm{~cm}^{-1}$ and 128 scans.

Proton nuclear magnetic resonance $\left({ }^{1} \mathrm{H}\right.$ NMR) was performed, and the spectra of lyophilized cellulose or 1-thio- $\beta$ D-glucose dissolved in $4 \%(\mathrm{w} / \mathrm{w}) \mathrm{NaOD}-\mathrm{D}_{2} \mathrm{O}(\sim 10 \mathrm{mg} / \mathrm{mL})$ were recorded on a Varian Inova-500 NMR spectrometer (Agilent Technologies, Santa Clara, CA, U.S.) at $30^{\circ} \mathrm{C}$ using VNMRJ 2.2D software. The ${ }^{1} \mathrm{H}$ NMR spectra were measured at $499.98 \mathrm{MHz}$ on a $5 \mathrm{~mm}$ indirect detection PFGprobe. The chemical shift was recorded relative to $\mathrm{D}_{2} \mathrm{O}\left(\delta_{\mathrm{H}}\right.$ 4.8). Spectral data were analyzed by MestReNova (https:// mestrelab.com).

Matrix-assisted laser desorption ionization time-of-flight mass spectrometry (MALDI-TOF MS) measurements were performed on a Bruker Autoflex Speed instrument (Bruker Daltonics, Billerica, MA, U.S.) using FlexControl 3.4 software. The cellulose suspension $(2-4 \mathrm{mg} / \mathrm{mL})$ was vacuum dried on a polished steel plate before the addition of matrix $(0.5 \mu \mathrm{L}$ of $2 \%$ (w/v) 2,5-dihydroxybenzoic acid in $30 \%$ (v/v) acetonitrile) and crystallization again under vacuum. The MS spectra were recorded in the range of $700-3000 \mathrm{~m} /$ $\mathrm{z}$ under reflector mode with the detector voltage set at $2217 \mathrm{kV}$ and processed by using Bruker FlexAnalysis 3.3.80 software (https://www.bruker.com). 

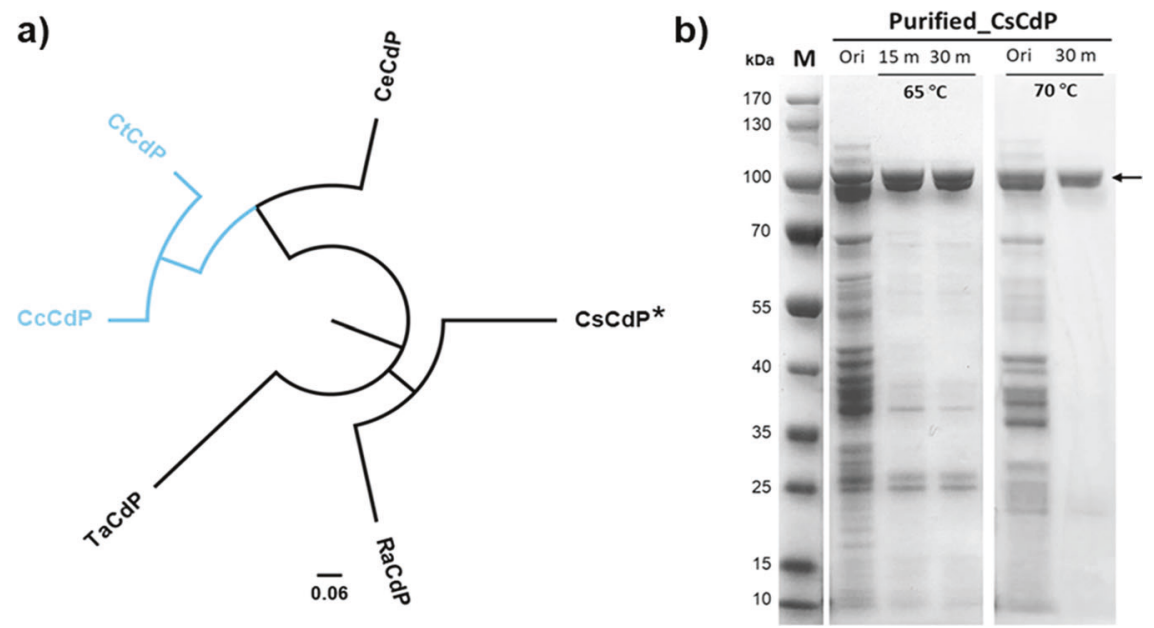

Fig. 1 Phylogenetic analysis of CdPs and isolation of CsCdP. a Phylogenetic tree of selected CdPs previously characterized biochemically. Multiple-sequence alignment was performed using ClustalX (http://www.clustal.org/). CdP gene origin: Ct, C. thermocellum (also known as Ruminiclostridium thermocellum); Cc, C. cellulosi; Ta,

\section{Results and discussion}

\section{Enzyme selection for synthesis of 1-thio-cellulose}

The synthesis of 1-thio-cellulose from 1-thio- $\beta$-D-glucose via a cascade reaction of $\mathrm{Cu} \mathrm{CbP}$ and $C c \mathrm{CdP}$ involves $\sim 40 \%$ plain cellulose, which is formed as a byproduct [32]. Glucose is required to build plain cellulose, and the $\alpha \mathrm{Glc1}$-P donor substrate is its source. The $C c \mathrm{CdP}$ used shows low hydrolase activity against $\alpha \mathrm{Glc} 1-\mathrm{P}(20.7 \pm 0.4 \mathrm{mU} / \mathrm{mg}) . \mathrm{CuCbP}$ forms cellobiose from the substrate glucose $(32.1 \mathrm{U} / \mathrm{mg})$, which shows a 51-fold increase in enzymatic production compared with 1-thio- $\beta$-D-glucose $(0.63 \mathrm{U} / \mathrm{mg})$. Cellobiose is an excellent substrate of $C c \mathrm{CdP}$ (13.3 U/mg), while 1-thio- $\beta$-D-glucose $(0.008 \mathrm{U} / \mathrm{mg})$ is not. The $\beta$-1,4-disaccharide of 1 -thio- $\beta$-Dglucose may be a better substrate than 1-thio- $\beta$-D-glucose, although it is unlikely to be used by $C c \mathrm{CdP}$ at a similar activity level as cellobiose. Therefore, limited synthesis precision of the enzymatic polymerization from 1-thio- $\beta$-D-glucose arises from "hydrolytic errors" made by $C c \mathrm{CdP}$ in the utilization of $\alpha \mathrm{Glc1}$ $P$ [32]. Considering the clear benefit for 1-thio-cellulose synthesis from the availability of a high-fidelity $\mathrm{CdP}$, we searched the sequence database and the relevant literature reports for alternative candidate enzymes from this class.

Sequence-based categorization of biochemically characterized CdPs in the form of a phylogenetic tree (Fig. 1a) shows that the $\mathrm{CdP}$ from $C$. thermocellum $(\mathrm{Ct} \mathrm{CdP}$; GenBank ID, BAB71818) is quite similar (75\% sequence identity) to the $C c \mathrm{CdP}$ used in our earlier study [32]. $C t \mathrm{CdP}$ has been reported by several groups for the synthesis of cello-oligosaccharides and cellulose [21, 22, 35]. Considering that similarity in the sequence often translates into
T. africanus TCF52B; Ra, R. albus; Cs, C. stercorarium; Ce, C. cellulovorans (GenBank ID, BAV13068.1). b SDS polyacrylamide gel showing purification of $C s \mathrm{CdP}$. Lane Ori shows the original enzyme stock after His-tag purification. The other lanes show the enzyme after heat treatment at the indicated temperature and time (in minutes (min))

similarity in the biochemical properties, we focused on enzymes more distant from $C c \mathrm{CdP}$ than $C t \mathrm{CdP}$. Among the candidates, CdP from C. stercorarium (Cs $\mathrm{CdP}$ ) was promising, particularly because it shares only $23 \%$ sequence identity with $C c \mathrm{CdP}$ and is permissive with respect to the acceptor substrate used. $\beta$-D-Glucosides with aromatic (e.g., 4-nitrophenol) and aliphatic aglycones (e.g., hexanol) are iteratively glycosylated from $\alpha \mathrm{Glc1-P}$ to form the corresponding glycosidic cello-oligosaccharides [36]. The CdPs from Thermosipho africanus TCF52B (TaCdP; GenBank ID, ACJ76363.1) and Ruminococcus albus (RaCdP; GenBank ID, ADU22883.1) are also distantly related to $C c \mathrm{CdP}$ (Fig. 1a). However, a biochemical characterization of these enzymes [37, 38] did not show activity with a glycoside acceptor. Thus, Cs CdP was the preferred choice for further study.

\section{Characterization of CsCdP}

Recombinant production of $C s \mathrm{CdP}$ in E. coli was previously reported [36], although a few points are worth noting here. The native $C s \mathrm{CdP}$ gene (GenBank ID, U60580.1) was expressed at a rather low level when the plasmid vector pTrc99A was used in E. coli XL10 Gold [36]. Using codon optimization, the gene expression in E. coli BL21(DE3) with plasmid vector pET-21b(+) was enhanced by a large amount, although most of the produced $C s \mathrm{CdP}(\sim 85 \%)$ was found in inclusion bodies. The tendency of $C s \mathrm{CdP}$ to become insoluble was retained under the various conditions of expression examined (Supplementary Fig. S3). An analysis of the cell extract by SDS polyacrylamide was performed to estimate the maximum 


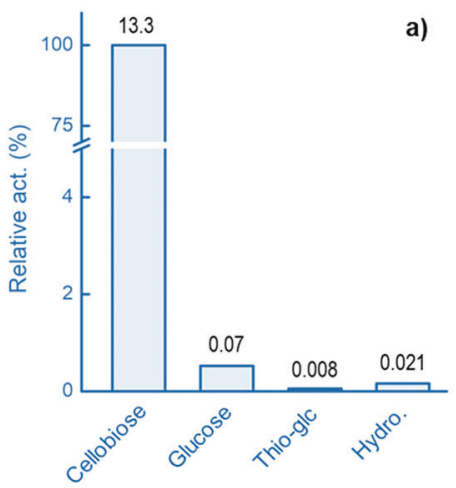

Fig. 2 Activity characterization of a $C c \mathrm{CdP}$, b $C s \mathrm{CdP}$, and $\mathbf{c} C u \mathrm{CbP}$ : the synthetic activity on glucose and 1 -thio- $\beta$-D-glucose (thio-glc) and $\alpha$ Glc1-P hydrolase activity (hydro.) are compared to the activity on cellobiose (at $45^{\circ} \mathrm{C}$ ). Synthetic activity was measured in MES buffer

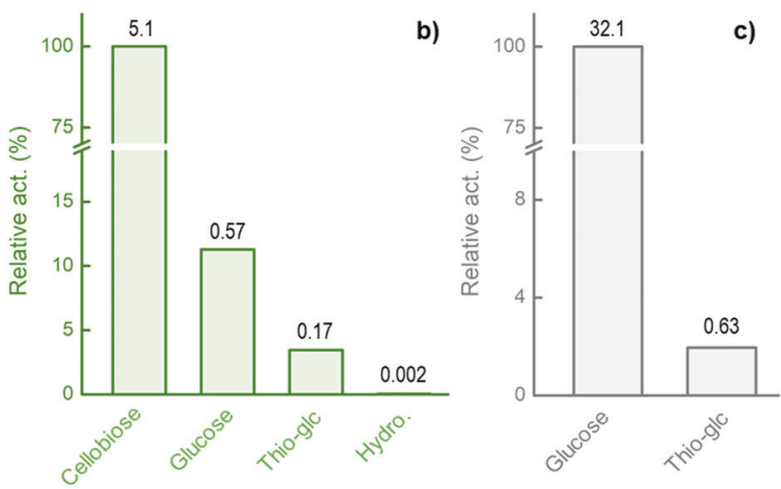

(pH 7.0) containing $\alpha \mathrm{Glc} 1-\mathrm{P}(50 \mathrm{mM})$ and the corresponding acceptor $(50 \mathrm{mM}) . \alpha \mathrm{Glc1}-\mathrm{P}$ hydrolase activity was measured in MES buffer $(\mathrm{pH}$ 7.0) containing $\alpha$ Glc1-P $(100 \mathrm{mM})$. The values above the columns indicate the specific activity $(\mathrm{U} / \mathrm{mg}$ ) of the corresponding enzyme production yield of soluble $C s \mathrm{CdP}$, which was $8 \mathrm{mg} / \mathrm{L}$ bacterial culture. $C s \mathrm{CdP}$ is equipped with a His tag at its N-terminus. Supplementary Fig. S2 shows the full amino acid sequence of the enzyme used. Purification led to enrichment of $C s \mathrm{CdP}$ in the enzyme preparation, although contaminating proteins remained in substantial amounts (Fig. 1b). Considering that $C s \mathrm{CdP}$ is heat resistant (half-life at $60{ }^{\circ} \mathrm{C}: \sim 30 \mathrm{~h} \mathrm{[39]),} \mathrm{we} \mathrm{used} \mathrm{temperature-induced} \mathrm{dena-}$ turation of the less thermostable E. coli proteins as a means of further purification of $C s \mathrm{CdP}$ (Fig. 1b). The yield of purified $C s C d P$ was $\sim 6 \mathrm{mg} / \mathrm{L}$ of culture. $C s C d P$ did not lose activity during the heat treatment, suggesting that the purified enzyme should be of good quality despite the thermal stress used. The specific activity of the purified $C s \mathrm{CdP}$ for the reaction with cellobiose and $\alpha \mathrm{Glc} 1-\mathrm{P}(5.1 \mathrm{U} / \mathrm{mg})$ was comparable with that from an earlier study of the enzyme (9.2 U/mg; [39]). This result is also reasonably in line with the specific activities of other CdPs assayed under relevantly comparable conditions ( $C c \mathrm{CdP}: 13.3 \mathrm{U} / \mathrm{mg}$ [19]; $C t$ CdP: 5.5 U/mg [40]; RaCdP: 20.4 U/mg [38]).

Figure 2 compares the relevant specific activities of $C s \mathrm{CdP}$ with those of $C c \mathrm{CdP}$ and $C u \mathrm{CbP}$. Although $C s \mathrm{CdP}$ was 2.6-fold less active than $C c \mathrm{CdP}$ on cellobiose, it retained considerably higher activities than $C c \mathrm{CdP}$ on glucose $(11 \% ; 8$-fold) and 1 -thio- $\beta$-D-glucose $(3.4 \% ; 21$-fold $)$ relative to cellobiose. The specific activity of $C s \mathrm{CdP}$ with 1 thio- $\beta$-D-glucose thus surpassed that of $C c \mathrm{CdP}$ by 21 -fold. The presence of the $\beta$-thio group diminished the activity of $C s \mathrm{CdP}$ (3.35-fold) less than that of $C c \mathrm{CdP}$ (8.8-fold) compared to the $\alpha / \beta$-hydroxy group in D-glucoside/D-glucose acceptors. The activity of $C s \mathrm{CdP}$ with 1 -thio- $\beta$-D-glucose was reasonably comparable (3.7-fold lower) to that of $\mathrm{CuCbP}$.

Most importantly, $C s \mathrm{CdP}$ showed hydrolase activity toward $\alpha$ Glc1-P that was approximately 11 -fold lower than that of $C c \mathrm{CdP}$. We confirmed the result of our earlier paper that $C u \mathrm{CbP}$ was inactive toward hydrolyzing $\alpha$ Glc1-P within the limits of detection [32]. Comparing the transfer activity with 1-thio- $\beta$-D-glucose to the hydrolase activity with $\alpha \mathrm{Glc} 1-\mathrm{P}, C s \mathrm{CdP}$ involved a reaction selectivity of $85(=0.17 / 0.002)$, which was 224 fold greater than that of $C c \operatorname{CdP}(0.38=0.008 / 0.021)$. The use of CdP enzyme selection for a direct (i.e., singleenzyme-catalyzed) iterative $\beta$-1,4-glycosylation of 1-thio$\beta$-D-glucose with very high product selectivity was strongly supported by these results. The activity data (Fig. 2) imply that the enzyme cascade with $C u \mathrm{CbP}$ can provide only a modest benefit for the conversion of 1-thio$\beta$-D-glucose. A simpler reaction with only a single enzyme (CsCdP) might suffice (Scheme 1b). The transfer/hydrolase selectivity of $C s \mathrm{CdP}$ suggests that the formation of plain cellulose should be minimal in the synthesis of cello-oligosaccharides from 1-thio- $\beta$-D-glucose. Differences between $C s \mathrm{CdP}$ and $C c \mathrm{CdP}$ in reactivity might be due to structural changes in the acceptor binding pocket, namely, the +2 subsite, which binds the reducing-end glucose residue of cellobiose, as discussed in other papers $[36,41,42]$.

\section{Enzymatic synthesis of 1-thio-cellulose}

Cellulose synthesis was performed using $100 \mathrm{mM} \alpha \mathrm{Glc} 1-\mathrm{P}$ and $10 \mathrm{mM} 1$-thio- $\beta$-D-glucose. The concentrations of donor and acceptor substrates were inspired by earlier work [32], in which insoluble product formation was favored under these conditions. Note that the glucosyl units transferred from the $\alpha$ Glc1-P substrate are distributed between soluble and insoluble oligosaccharide products. A high donor/ acceptor ratio shifts the distribution toward the desired insoluble material. The reactions of $C s \mathrm{CdP}$ alone or in 


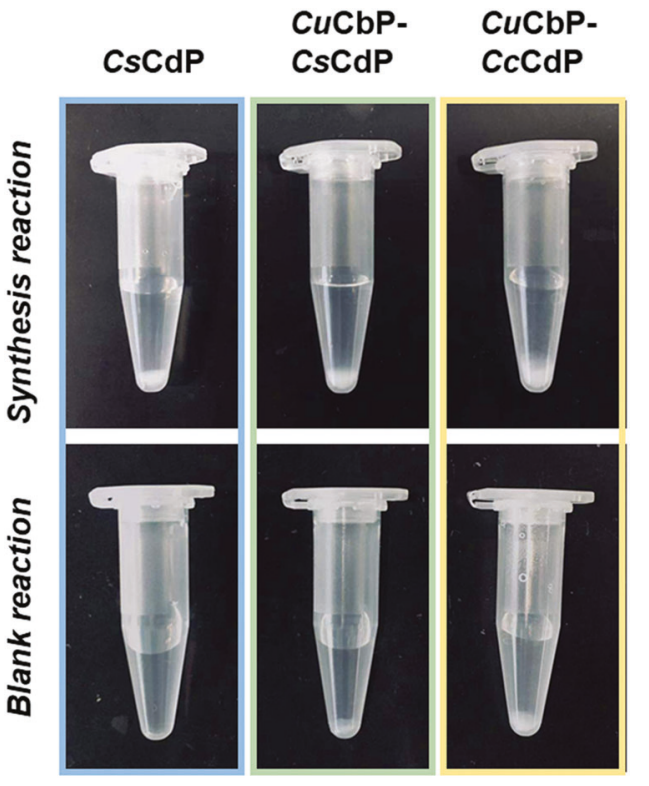

Fig. 3 Photographic images showing the reaction mixture of the single enzyme $(C s \mathrm{CdP})$ and coupled enzyme $(\mathrm{CbP}-\mathrm{CdP})$ reactions. Synthesis reactions containing $100 \mathrm{mM} \alpha \mathrm{Glc} 1-\mathrm{P}$ and $10 \mathrm{mM} 1$-thio- $\beta$-D-glucose in MES buffer $(50 \mathrm{mM}, \mathrm{pH} 7.0)$ were carried out at $45^{\circ} \mathrm{C}$ for $8 \mathrm{~h}$ $(C s \mathrm{CdP}$ reaction) and $12 \mathrm{~h}$ (CbP-CdP reaction). Blank reactions were performed using otherwise exactly identical conditions but lacking 1-thio- $\beta$-D-glucose

combination with $\mathrm{Cu} \mathrm{CbP}$ were compared to a reference reaction of $C c \mathrm{CdP}$ and $\mathrm{CuCbP}$.

As shown in Fig. 3, all reactions involved a whitish precipitate formed with time. Importantly, the blank reaction in the absence of 1-thio- $\beta$-D-glucose did not show the precipitate or only showed a slight amount when CsCdP was used with or without $\mathrm{CuCbP}$. In contrast, the blank reaction of the reference produced a substantial amount of precipitate. This finding was consistent with the expectation and supported by the activity data in Fig. 2, which showed that the hydrolysis of $\alpha \mathrm{Glc1} 1 \mathrm{P}$ catalyzed by $C c \mathrm{CdP}$ promotes cellulose formation via glucose release (Supplementary Fig. S1). These results also imply the formation of 1-thio-cellulose in higher purity when $C s C d P$ is used instead of $C c \mathrm{CdP}$.

The $\alpha$ Glc1-P conversion in the synthesis reactions was measured from the released phosphate. Reactions of $C s \mathrm{CdP}$ proceeded at a similar rate when $C u \mathrm{CdP}$ was absent or present. The conversion yield reached $\sim 25 \mathrm{~mol}$ $\%$ after $8 \mathrm{~h}$, which leaves room for optimization. The equilibrium for polymerization from $\alpha \mathrm{Glc1}-\mathrm{P}$ is complex when an insoluble product is formed. Generally, from the reaction in solution analyzed in detail for $C c \mathrm{CdP}$, one would expect that $\alpha$ Glc1-P conversion of $\sim 60 \mathrm{~mol} \%$ should be thermodynamically possible. By comparison, the conversion yield of the $C u \mathrm{CbP}-C c \mathrm{CdP}$ reference reaction was $\sim 41 \mathrm{~mol} \%$.

\section{Structural characterization of the thio-cello- oligosaccharide chains}

The insoluble product of enzymatic synthesis was analyzed by MALDI-TOF-MS. As shown in Fig. 4, the mass spectra showed a series of peaks $\left([\mathrm{M}+\mathrm{Na}]^{+}\right)$with peak-to-peak mass differences of $162 \mathrm{Da}$, which is consistent with the mass of a single glucosyl unit in cellulose chains [35, 43]. The product from the $C u \mathrm{CbP}-C c \mathrm{CdP}$ reference reaction exhibited two main groups of peaks assigned to the cellooligosaccharides in the DP range 6-11, and they contained and lacked a single thiol group (Fig. 4a). The product from the $C s \mathrm{CdP}$ reaction without $C u \mathrm{CbP}$ (Fig. 4b) or with $\mathrm{CuCbP}$ (Fig. 4c) showed peak clusters assigned to 1-thiocellulose chains of DP of 7-17 at an estimated purity of $\sim 95 \%$. Although plain cello-oligosaccharides were detectable (Fig. 4), their abundance was low ( $\leq 5 \%$ of total product; single $C s C d P$ reaction). The central idea of this study, that a purer 1-thio-cellulose product can be synthesized by selection of a $\mathrm{CdP}$ more suitable than $C c \mathrm{CdP}$, was confirmed by this evidence. Of note, the peak cluster at each DP, with masses differing in $\mathrm{m} / \mathrm{z}$ by $+16 / 32 / 48 / 64$ units from the corresponding plain cellulose chain $(*)$, was assigned to different oxidation states of the 1-thio-cellulose chain. As shown elsewhere for the general case of thiol groups in polymers [44], the original $-\mathrm{SH}$ group of the cellulose chain can be oxidized to $-\mathrm{SO}_{x} \mathrm{H}$ under the conditions of the MS analysis, with $x$ varying between 1 and 3 . The average polymer DP from the reaction with $C s \mathrm{CdP}$ $\left(\mathrm{DP}_{\mathrm{av}}=9.7\right)$ differed from that of the reference reaction $\left(\mathrm{DP}_{\mathrm{av}}=8.1\right)$. The longest chain detectable with the MALDI-TOF-MS analysis was larger for the $C s \mathrm{CdP}$ reactions $\left(\mathrm{DP}_{\max }=17\right)$ compared to the reference reaction $\left(\mathrm{DP}_{\max }=11\right)$. The cellulose synthesized by $C s \mathrm{CdP}$ exhibited a broader distribution of oligosaccharide DP than the cellulose synthesized by $C c \mathrm{CdP}$ (Fig. 4). The difference in the DP distribution of the produced cellulose chains likely reflects the individual specificities of the CdP enzymes used. Kinetic parameters (e.g., maximum rate constant) for each step of glycosyl transfer in the iterative process of polymerization can depend on the DP of the nascent cellooligosaccharide, which was shown in a recent study of cello-oligosaccharide synthesis by $C c \mathrm{CdP}$ [45]. The glycosylation rate dropped substantially ( $\sim 3$-fold) once the acceptor DP reached a value of 6 , thus suggesting an explanation for the particular DP distribution observed. A reaction time course analysis is not available for $C s \mathrm{CdP}$. However, the shift of DP distribution to higher $\mathrm{DP}_{\mathrm{av}}$ and $\mathrm{DP}_{\max }$ compared to $C c \mathrm{CdP}$ would imply that $C s \mathrm{CdP}$ exhibits a relatively smaller dependence of its activity on the acceptor substrate DP in the relevant DP range from 7 to 17 . Previous studies of CdP-catalyzed synthesis of cellooligosaccharides show that reaction conditions (e.g., molar 
Fig. 4 MALDI-TOF MS spectra of cellulose materials synthesized from a $C u \mathrm{CbP}-C c \mathrm{CdP}$; b $C s \mathrm{CdP}$; and $\mathbf{c} C u \mathrm{CbP}-\mathrm{Cs} \mathrm{CdP}$ reaction. At each DP range, the peak of plain cellulose was indicated by the symbol *, and the following clusters $(+16 / 32 / 48 / 64 \mathrm{~m} / \mathrm{z}$ as to the plain cellulose) were assigned to the 1-thio-cellulose and thiol oxidation products thereof: the peak $(+16 \mathrm{~m} / \mathrm{z})$ marked by the blue line was assigned to cellooligomer-SH; the peak $(+64 \mathrm{~m} / \mathrm{z})$ marked by the green line was assigned to cello-oligomer- $\mathrm{SO}_{3} \mathrm{H}$; and the area in between were the peaks $(+32 / 48 \mathrm{~m} / \mathrm{z})$ of oligomer$\mathrm{SOH} / \mathrm{SO}_{2} \mathrm{H}$
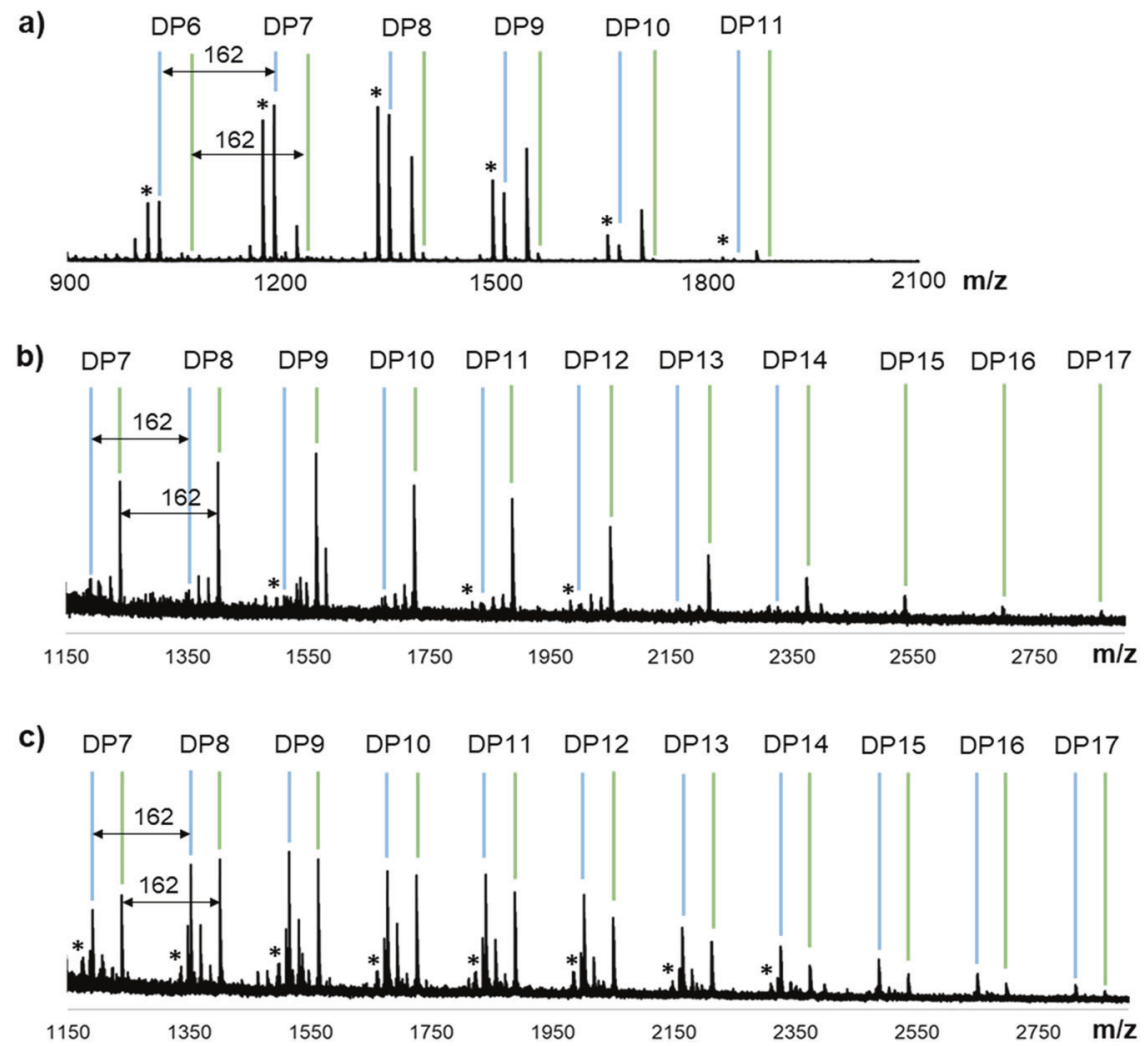

ratio of donor and acceptor substrate; overall polymerization rate) also affect the DP distribution in the insoluble product. The reaction of $C s \mathrm{CdP}$ led to a lower conversion of the $\alpha$ Glc1-P substrate $(\sim 25 \mathrm{~mol} \%)$ than the reference reaction $(\sim 40 \mathrm{~mol} \%)$. The substrate conversion might affect the DP distribution in the insoluble product indirectly via its effect on the concentration and aggregation rate of the growing cello-oligosaccharides in solution [46]. However, an analysis of the $C c \mathrm{CdP}$ reaction with cellobiose as the substrate $(10 \mathrm{mM} ; 150 \mathrm{mM} \alpha \mathrm{Glc} 1-\mathrm{P})$ also gave a $\mathrm{DP}_{\max }$ of 11 (data not shown). This result supported the idea that the DP distribution was mainly due to the enzyme used, i.e., $C c \mathrm{CdP}$ or $C s \mathrm{CdP}$. The importance of the choice of $\mathrm{CdP}$ enzyme was thus supported.

The synthesized celluloses were further characterized by ${ }^{1} \mathrm{H}-\mathrm{NMR}$ in solution. Solid material dissolved in $4 \%(\mathrm{w} / \mathrm{w})$ $\mathrm{NaOD}-\mathrm{D}_{2} \mathrm{O}$ was analyzed. The spectra showed signals assigned to the repeating $\beta$-glucosyl units of cellulose (Fig. 5) [47]. The dominant doublet at approximately $\delta_{\mathrm{H}}$ 4.30 was assigned to the internal $\beta-1,4$ glycosidic linkages $\left(\mathrm{H}_{1}\right)$ in cellulose $[21,46]$. By reference to the acceptor (1thio- $\beta$-D-glucose), the doublet signal at $\delta_{\mathrm{H}} 4.35$ ( $J$-coupling constant of $8.9 \mathrm{~Hz}$ ) was ascribed to the anomeric proton $\left(\mathrm{H}_{1},\right)$ of the terminal $\beta$-1-thio-glucose residue in the 1-thiocellulose chain. Here, we noticed that the signals at $\delta_{\mathrm{H}} 5.1$ and 4.5, which are assigned to the $\alpha$ - and $\beta$-anomeric protons on the reducing end of plain cellulose [19, 21, 22], were only detected in the spectra of the product from the $C u \mathrm{CbP}-C c \mathrm{CdP}$ reference reaction (Fig. $5 \mathrm{~b}$ ). No unassigned signals were present in the full ${ }^{1} \mathrm{H}-\mathrm{NMR}$ spectra of the product from the $C s C d P$ reaction (Fig. 5a). This result was consistent with the evidence from the mass analysis, thus indicating a highly pure 1-thio-cellulose obtained from the $C s \mathrm{CdP}$ reaction. Moreover, based on the signal intensity of the anomeric protons at internal sites $\left(\delta_{\mathrm{H}} 4.30\right)$ and at the terminal residue $\left(\delta_{\mathrm{H}} 4.35\right)$, a value of 10.3 was determined for $\mathrm{DP}_{\mathrm{av}}$ in the material from the $C s \mathrm{CdP}$ reaction, which is comparable to the value $\left(\mathrm{DP}_{\mathrm{av}}=9.7\right)$ determined by MALDI-TOF-MS, thus indicating the validity of both analyses. Overall, the results shown confirm the expected chemical structure of the reducing-end thiol-modified cellooligosaccharides and further support the idea of using CsCdP for precision synthesis of 1-thio-cellulose material.

\section{Material characterization of the as-synthesized 1-thio-cellulose}

XRD and ATR-FTIR were used, and the cellulose from the single-enzyme reaction of $C s \mathrm{CdP}$ was analyzed and compared to the sample from the $C u \mathrm{CbP}-C c \mathrm{CdP}$ reference reaction. Figure 6 shows that the spectral properties of the two celluloses were similar. The XRD patterns of both 

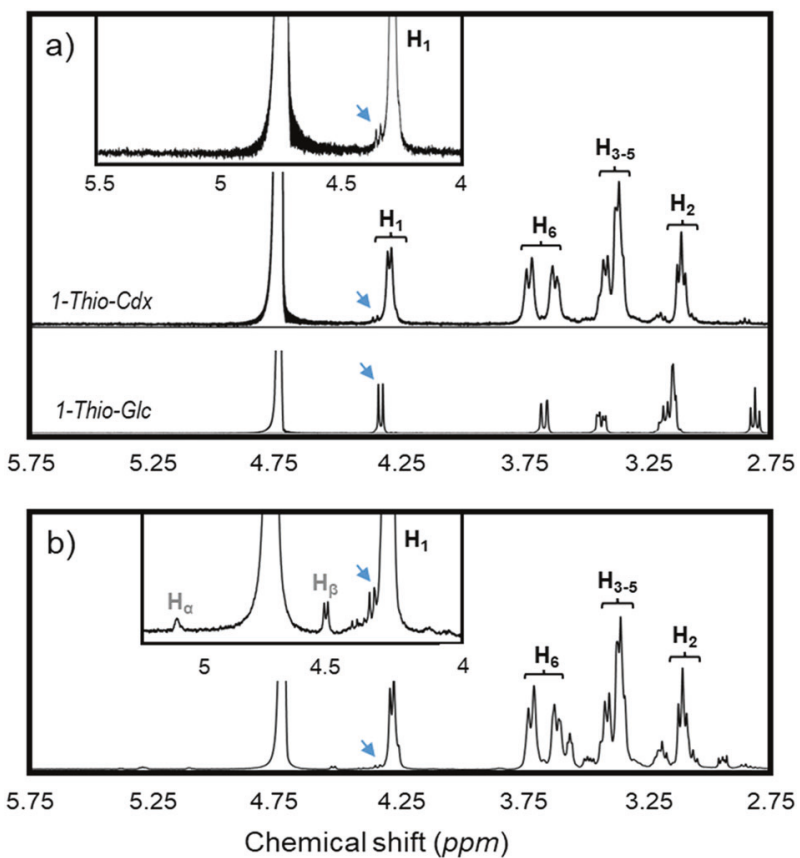

Fig. $5{ }^{1} \mathrm{H}-\mathrm{NMR}$ profile of cellulose materials synthesized from the a $C s C d P$ reaction (profile of acceptor 1 -thio- $\beta$-D-glucose was included) and $\mathbf{b} C u \mathrm{CbP}-C c \mathrm{CdP}$ reaction. In each panel, the inset showing the enlarged region for anomeric protons was added

samples exhibited diffraction peaks $\left(2 \theta\right.$ at $12.3^{\circ}, 20.0^{\circ}$, and $22.1^{\circ}$ ) that were assigned to the $1 \overline{1} 0,110$ and 020 faces of crystalline cellulose II (Fig. 6a), respectively [48]. The sharp XRD peaks suggest a highly crystalline material. In addition, the ATR-FTIR spectra of both samples showed prominent absorbance bands at 3441 and $3490 \mathrm{~cm}^{-1}$ (Fig. 6b). The two bands are characteristic of the $\mathrm{OH}-$ stretching intramolecular hydrogen bonds present in crystalline cellulose II [49, 50]. Overall, therefore, these results indicate self-assembly of the pure 1-thio-cellooligosaccharides into crystalline cellulose of allomorph II crystal structure. The absence of plain cello-oligosaccharide chains in the synthetic reaction of $C s \mathrm{CdP}$ apparently does not affect the recorded characteristics of the material structure in the cellulose obtained. The change in DP distribution in the $C s \mathrm{CdP}$ reaction compared to the reference reaction also seems to have no influence on the material properties analyzed. Organization of the synthetic oligomer chains into crystalline material appears to be independent of the CdP enzyme used, which is consistent with the idea of a spontaneous process based on self-assembly-driven chain association. Considering the antiparallel arrangement of the oligosaccharide chains in cellulose II, earlier studies $[14,32]$ seem to suggest that the functional thiol groups are regularly distributed on the two base planes (surfaces) of the 1-thio-cellulose material. Taken together, the current study demonstrates a highly crystalline material (cellulose II allomorph) composed of pure 1-thio-cellulose chains with
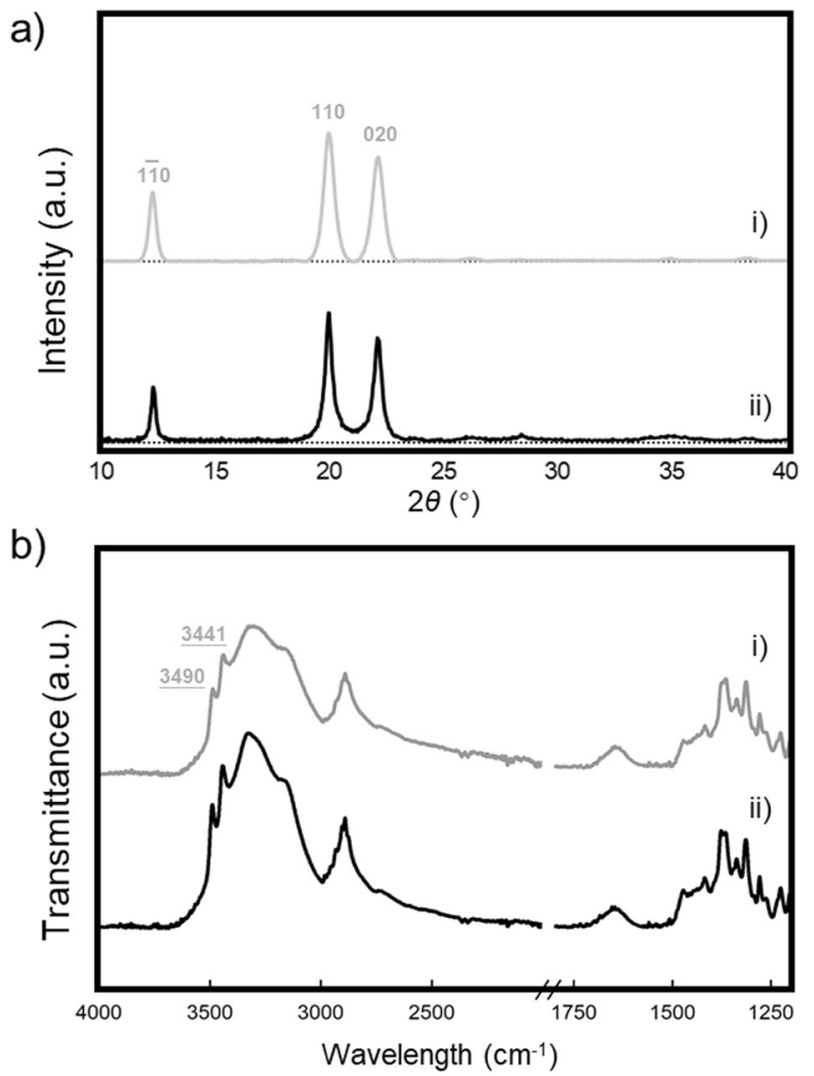

Fig. 6 Structural characterization of the synthetic 1-thio-cellulose: a XRD patterns and $\mathbf{b}$ ATR-FTIR spectra. In each panel, the materials synthesized from the $C s \mathrm{CdP}$ reaction and the $C u \mathrm{CbP}-C c \mathrm{CdP}$ reaction are indicated as (i) and (ii), respectively

an average DP of $\sim 10$. Identification of $C s \mathrm{CdP}$ as a specific "cello-oligosaccharide polymerase" was essential to achieve precision synthesis of the material. We expect that access to well-defined 1-thio-cellulose can facilitate further functional diversification of nanocellulose materials in the future.

\section{Conclusions}

$C s \mathrm{CdP}$ was identified as a catalyst for the preparation of pure 1-thio-cellulose ( $\geq 95 \%)$. Cs CdP differs from $C c \mathrm{CdP}$ in two important respects. The lower activity of $C s \mathrm{CdP}$ for hydrolyzing $\alpha \mathrm{Glc} 1-\mathrm{P}$ ( 11 -fold) is essential for high synthetic precision, while the higher activity of $C s \mathrm{CdP}$ for the reaction with 1 -thio- $\beta$-D-glucose ( 21 -fold) obviates the need for additional $\mathrm{CbP}$ and enables a practical reaction using only a single enzyme. The $C s C d P$ reaction provides highly crystalline 1-thio-cellulose of allomorph II crystal structure involving oligosaccharides with $\mathrm{DP}_{\mathrm{av}}$ of $\sim 10$. The incorporation of thiol groups into crystalline cellulose in a topochemically defined fashion may be used for further functional diversification of nanocellulose materials. 


\section{Data availability}

Data from the current study are available from https://doi. org/10.5281/zenodo.5628181.

Acknowledgements This project received funding from the European Union's Horizon 2020 research and innovation program under grant agreement no. 761030 (CARBAFIN). The authors acknowledge Prof. Hansjörg Weber and Prof. Brigitte Bitschnau from Graz University of Technology for the ${ }^{1} \mathrm{H}$ NMR and XRD support, respectively. The authors also thank Prof. Iain Wilson and Dr. Jorick Vanbeselaere from the University of Natural Resources and Life Sciences (Vienna) for MALDI-TOF MS support.

\section{Compliance with ethical standards}

Conflict of interest The authors declare no competing interests.

Publisher's note Springer Nature remains neutral with regard to jurisdictional claims in published maps and institutional affiliations.

Open Access This article is licensed under a Creative Commons Attribution 4.0 International License, which permits use, sharing, adaptation, distribution and reproduction in any medium or format, as long as you give appropriate credit to the original author(s) and the source, provide a link to the Creative Commons license, and indicate if changes were made. The images or other third party material in this article are included in the article's Creative Commons license, unless indicated otherwise in a credit line to the material. If material is not included in the article's Creative Commons license and your intended use is not permitted by statutory regulation or exceeds the permitted use, you will need to obtain permission directly from the copyright holder. To view a copy of this license, visit http://creativecommons. org/licenses/by/4.0/

\section{References}

1. Abitbol T, Rivkin A, Cao Y, Nevo Y, Abraham E, Ben-Shalom T, et al. Nanocellulose, a tiny fiber with huge applications. Curr Opin Biotechnol. 2016;39:76-88.

2. Salas C, Nypelö T, Rodriguez-Abreu C, Carrillo C, Rojas OJ. Nanocellulose properties and applications in colloids and interfaces. Curr Opin Colloid Interface Sci. 2014;19:383-96.

3. Kontturi E, Laaksonen P, Linder MB, Nonappa, Gröschel AH, Rojas OJ, et al. Advanced materials through assembly of nanocelluloses. Adv Mater. 2018;30:1703779.

4. Jorfi M, Foster EJ. Recent advances in nanocellulose for biomedical applications. J Appl Polym Sci. 2015;132:41719.

5. Yang Y, Lu Y-T, Zeng K, Heinze T, Groth T, Zhang K. Recent progress on cellulose-based ionic compounds for biomaterials. Adv Mater. 2021;33:2000717.

6. Hickey RJ, Pelling AE. Cellulose biomaterials for tissue engineering. Front Bioeng Biotechnol. 2019;7.

7. Bacakova L, Pajorova J, Bacakova M, Skogberg A, Kallio P, Kolarova K, et al. Versatile application of nanocellulose: from industry to skin tissue engineering and wound healing. Nanomaterials. 2019;9:164

8. Squinca P, Bilatto S, Badino AC, Farinas CS. Nanocellulose production in future biorefineries: an integrated approach using tailor-made enzymes. ACS Sustain Chem Eng. 2020;8:2277-86.

9. Xue Y, Mou Z, Xiao H. Nanocellulose as a sustainable biomass material: structure, properties, present status and future prospects in biomedical applications. Nanoscale. 2017;9:14758-81.
10. Sunasee R, Hemraz UD. Synthetic strategies for the fabrication of cationic surface-modified cellulose nanocrystals. Fibers. 2018;6:15.

11. Li Y-Y, Wang B, Ma M-G, Wang B. Review of recent development on preparation, properties, and applications of cellulosebased functional materials. Int J Polym Sci. 2018;2018:1-18.

12. Trache D, Tarchoun AF, Derradji M, Hamidon TS, Masruchin N, Brosse N, et al. Nanocellulose: from fundamentals to advanced applications. Front Chem. 2020;8:392.

13. Shoda S-i, Uyama H, Kadokawa J-I, Kimura S, Kobayashi S. Enzymes as green catalysts for precision macromolecular synthesis. Chem Rev. 2016;116:2307-413.

14. Nidetzky B, Zhong C. Phosphorylase-catalyzed bottom-up synthesis of short-chain soluble cello-oligosaccharides and property-tunable cellulosic materials. Biotechnol Adv. 2020;51: 107633.

15. Billès E, Coma V, Peruch F, Grelier S. Water-soluble cellulose oligomer production by chemical and enzymatic synthesis: a minireview. Polym Int. 2017;66:1227-36.

16. Nakai H, Kitaoka M, Svensson B, Ohtsubo K. Recent development of phosphorylases possessing large potential for oligosaccharide synthesis. Curr Opin Chem Biol. 2013;17:301-9.

17. Tu H, Zhu M, Duan B, Zhang L. Recent progress in high-strength and robust regenerated cellulose materials. Adv Mater. 2021;33:2000682.

18. Bulmer GS, de Andrade P, Field RA, van Munster JM. Recent advances in enzymatic synthesis of $\beta$-glucan and cellulose. Carbohydr Res. 2021;508:108411.

19. Zhong C, Luley-Goedl C, Nidetzky B. Product solubility control in cellooligosaccharide production by coupled cellobiose and cellodextrin phosphorylase. Biotechnol Bioeng. 2019;116:2146-55.

20. Egusa S, Kitaoka T, Goto M, Wariishi H. Synthesis of cellulose in vitro by using a cellulase/surfactant complex in a nonaqueous medium. Angew Chem Int Ed. 2007;46:2063-5.

21. Hiraishi M, Igarashi K, Kimura S, Wada M, Kitaoka M, Samejima M. Synthesis of highly ordered cellulose II in vitro using cellodextrin phosphorylase. Carbohydr Res. 2009;344:2468-73.

22. Serizawa T, Kato M, Okura H, Sawada T, Wada M. Hydrolytic activities of artificial nanocellulose synthesized via phosphorylasecatalyzed enzymatic reactions. Polym J. 2016;48:539-44.

23. Yataka Y, Sawada T, Serizawa T. Enzymatic synthesis and postfunctionalization of two-dimensional crystalline cellulose oligomers with surface-reactive groups. Chem Commun. 2015;51: $12525-8$.

24. Adharis A, Petrović DM, Özdamar I, Woortman AJJ, Loos K. Environmentally friendly pathways towards the synthesis of vinylbased oligocelluloses. Carbohydr Polym. 2018;193:196-204.

25. de Andrade P, Muñoz-García JC, Pergolizzi G, Gabrielli V, Nepogodiev SA, Iuga D, et al. Chemoenzymatic synthesis of fluorinated cellodextrins identifies a new allomorph for celluloselike materials. Chem Eur J. 2021;27:1374.

26. Leichner C, Jelkmann M, Bernkop-Schnurch A. Thiolated polymers: bioinspired polymers utilizing one of the most important bridging structures in nature. Adv Drug Deliv Rev. 2019;151-152:191-221.

27. Lowe AB. Thiol-ene "click" reactions and recent applications in polymer and materials synthesis: a first update. Polym Chem. 2014;5:4820-70.

28. Lowe AB, Hoyle CE, Bowman CN. Thiol-yne click chemistry: a powerful and versatile methodology for materials synthesis. J Mater Chem. 2010;20:4745-50.

29. Li H, Yu B, Matsushima H, Hoyle CE, Lowe AB. The thiolisocyanate click reaction: facile and quantitative access to $\omega$-endfunctional $\operatorname{Poly}(N, N$-diethylacrylamide) synthesized by RAFT radical polymerization. Macromolecules. 2009;42:6537-42.

30. Adzima BJ, Bowman CN. The emerging role of click reactions in chemical and biological engineering. AIChE J. 2012;58:2952-65. 
31. Hoyle CE, Lowe AB, Bowman CN. Thiol-click chemistry: a multifaceted toolbox for small molecule and polymer synthesis. Chem Soc Rev. 2010;39:1355-87.

32. Zhong C, Zajki-Zechmeister K, Nidetzky B. Reducing end thiolmodified nanocellulose: bottom-up enzymatic synthesis and use for templated assembly of silver nanoparticles into biocidal composite material. Carbohydr Polym. 2021;260:117772

33. An, Jeon B, Bae JH, Kim IS, Paeng K, Kim M, Lee H. Thiol-based chemistry as versatile routes for the effective functionalization of cellulose nanofibers. Carbohydr Polym. 2019;226:115259.

34. Saheki S, Takeda A, Shimazu T. Assay of inorganic phosphate in the mild $\mathrm{pH}$ range, suitable for measurement of glycogen phosphorylase activity. Anal Biochem. 1985;148:277-81.

35. Pylkkänen R, Mohammadi P, Arola S, de Ruijter JC, Sunagawa N, Igarashi K, et al. In vitro synthesis and self-assembly of cellulose II nanofibrils catalyzed by the reverse reaction of Clostridium thermocellum cellodextrin phosphorylase. Biomacromolecules. 2020;21: 4355-64.

36. Tran GH, Desmet T, De Groeve MRM, Soetaert W. Probing the active site of cellodextrin phosphorylase from Clostridium stercorarium: kinetic characterization, ligand docking, and sitedirected mutagenesis. Biotechnol Prog. 2011;27:326-32.

37. Wu Y, Mao G, Fan H, Song A, Zhang YP, Chen H. Biochemical properties of GH94 cellodextrin phosphorylase THA_1941 from a thermophilic eubacterium Thermosipho africanus TCF52B with cellobiose phosphorylase activity. Sci Rep. 2017;7:4849.

38. Sawano T, Saburi W, Hamura K, Matsui H, Mori H. Characterization of Ruminococcus albus cellodextrin phosphorylase and identification of a key phenylalanine residue for acceptor specificity and affinity to the phosphate group. FEBS J. 2013;280: 4463-73.

39. Reichenbecher M, Lottspeich F, Bronnenmeier K. Purification and properties of a cellobiose phosphorylase (CepA) and a cellodextrin phosphorylase (CepB) from the cellulolytic thermophile Clostridium stercorarium. Eur J Biochem. 1997;247:262-7.

40. Shintate K, Kitaoka M, Kim Y-K, Hayashi K. Enzymatic synthesis of a library of $\beta$-(1-4) hetero-d-glucose and D-xylose-based oligosaccharides employing cellodextrin phosphorylase. Carbohydr Res. 2003;338:1981-90.

41. O’Neill EC, Pergolizzi G, Stevenson CEM, Lawson DM, Nepogodiev SA, Field RA. Cellodextrin phosphorylase from Ruminiclostridium thermocellum: X-ray crystal structure and substrate specificity analysis. Carbohydr Res. 2017;451:118-32.

42. Gabrielli V, Muñoz-García JC, Pergolizzi G, de Andrade P, Khimyak YZ, Field RA, et al. Molecular recognition of natural and non-natural substrates by cellodextrin phosphorylase from Ruminiclostridium thermocellum investigated by NMR spectroscopy. Chem Eur J. 2021;27:15688.

43. Hata Y, Sawada T, Serizawa T. Effect of solution viscosity on the production of nanoribbon network hydrogels composed of enzymatically synthesized cellulose oligomers under macromolecular crowding conditions. Polym J. 2017;49:575-81.

44. Gaillot C, Delolme F, Fabre L, Charreyre M-T, Ladavière C, Favier A. Taking advantage of oxidation to characterize thiolcontaining polymer chains by MALDI-TOF mass spectrometry. Anal Chem. 2020;92:3804-9.

45. Klimacek M, Zhong C, Nidetzky B. Kinetic modeling of phosphorylase-catalyzed iterative $\beta$-1,4-glycosylation for degree of polymerization-controlled synthesis of soluble cellooligosaccharides. Biotechnol Biofuels. 2021;14:134.

46. Petrovic DM, Kok I, Woortman AJ, Ciric J, Loos K. Characterization of oligocellulose synthesized by reverse phosphorolysis using different cellodextrin phosphorylases. Anal Chem. 2015;87:9639-46.

47. Isogai A. NMR analysis of cellulose dissolved in aqueous $\mathrm{NaOH}$ solutions. Cellulose. 1997;4:99-107.

48. Hori R, Wada M. The thermal expansion of cellulose II and IIIII crystals. Cellulose. 2006;13:281-90.

49. Nelson ML, O'Connor RT. Relation of certain infrared bands to cellulose crystallinity and crystal latticed type. Part I. Spectra of lattice types I, II, III and of amorphous cellulose. J Appl Polym Sci. 1964;8:1311-24.

50. Carrillo F, Colom X, Suñol JJ, Saurina J. Structural FTIR analysis and thermal characterisation of lyocell and viscose-type fibres. Eur Polym J. 2004;40:2229-34. 